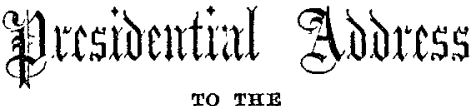

\section{MEMBERS OF THE ASSOCIATION OF MEDICAL OFFICERS OF HOSPITALS AND ASYLUMS FOR THE INSANE,}

\author{
At their Annual Meeting, held July 2nd, 1857, at the \\ Great Western Hotel.
}

\section{By FORBES WINSLOW, M.D., D.C.I.}

GeNTLEME:,--I have the honour of occupying on this occasion the distinguished position of your president, and in that capacity it is now my privilege and pleasure to appear before you.

Addressing myself to a body of gentlemen distinguished for their ability, experience, their knowledge of the morbid phenomena of mind, as well as practical acquaintance with the treatment of the insane, I ask, is it possible for me to give you any information you are not already fully in possession of?-is it in my power to impress upon your mind a higher appreciation of the noble and honourable vacation in which we are all engaged, than that which I believe you have already formed? I despair of bringing before this Association any novel facts in pathology or therapentics-any startling deductions calculated to excite your interest, attract your attention, or instruct your nnderstandings. However, I will, notwithstanding the obvious disadvantages under which I labour, venture-with, I trust, an unostentatious distrust in my own capacity either to inform or please-to address to my fellow-labourers in the great work of love and Christian philanthropy a few words in relation to the anxious, onerous, and often painful duties which devolve upon all engaged in the treatment of the insane. It is well that we should, from time to time, whilst occupied in life's pilgrimage, lean upon our staff, pause, and seriously consider the position it has pleased the will of Providence that we should occupy. It is right and befitting that we should occasionally solemnly reflect upon the PAST, dwell with earnestness upon the PRESENT, and seriously ponder over the FUTURE. In commercial phraseulogy, it is well that we should occasionally take stock, examine carefully our ledger, ascertain with accuracy the balance at the banker's, and consider with businesslike precision and exactitude our credit and dehtor account. This process of retrospection cannot be otherwise than beneficial to us all. It is right that the man occupied in the higher spheres of usefulness, who is cultivating the more abstruse and philosophical departments of the science and art of medicine; that he who is entrusted by the legrislature with the care and treatment of the insane, should frequently ask himself the question - what are the functions delegated to me? Do I entertain a right appreciation of my important duties, and am I so discharging them that at the great and final day of judgment I shall be in a position to give a good and faithful account of my stewardship?

Considering our vocation in its strictly scientific relations, need I observe, when comparing it with other branches of our noble profession, of which it forms a part, that the practical psychologist occupies high and honourable vantage ground.

It is not my intention to breathe a word in disparagement of other sections of the medical profession. Each class holds an honourable rank in the great circle of science; each division has allotted to it its own anxious and specific duties; and whatever position the practitioner of medisine may fill, whether it be that of a surgeon, a general or special physician, all in their separate and respective spheres of duty have responsible functions devolving upon them. But in what respect do we differ from other departments of the medical profession? What particular and specific functions are assigned to those engaged in the treatment of the insane? Whilst the physician devoted to general practice is administering to the plysical state of the system, -in healing abnormal conditions of matter interfering with the vital manifestations, - -we, as psychologists, take a more exalted Hight in the regions of science. It is our envialsle privilege to deal with the human mind-to study its healthy as well as disordered state, to investigate that SPIRITUAL aura, that DIVINE ISSENCE which is so mysteriously interwoven and associated with the grosser particles of the material fabric.

How noble is the study in which we are engaged! how important the duties that devolve upon us ! how solemnly respon. sible is our position! Is it possible to exaggerate or over-estimate our character, influence, importance, and dignity? What profound and accurate knowledge of the mind in its normal state do we not require before we are fitted successfully to investigate, unravel, and treat remedially its deviations from a healthy standard! How intimate must be our acquaintance with the phenomena of thought, and with the nature and operations of the passions. How exact should be our notions of the instinctive and perceptive faculties of the mind before we are fully qualified to appreciate subtle morbid psychical conditions!

We should entertain right notions of our duty and position; we should encourage elevated, lofty thoughts and grand conceptions of our honourable vocntion; we should impress repeatedly, earnestly, and emphatically upon our own understandings and the minds of all engaged in the same holy work the significant fact, that we are occupied in the study and treatment of a class of diseases affecting the very source, spring, and fountain of that principle which in its healthy operations alone can bring us into remote proximity to DEITY - that we hivve to deal with the spiritual part of man's complex nature, with that which elevates us in the scale of created excellencies, and places us high on the pedestal amongst the great, the good, and the wise. But our solemn functions expand in interest, gravity, and importance, as we reflect that it is mind prostrated, perverted, and often crushed by disease with which we, is practical physicians, have to deal. That we have placed under our care a class of the afficted human family, reduced by the inscrutable decrees of Providence to the most humiliating, degrading, and helpless position to which poor human nature can fall ; that it is our duty to witness the sad wreck of great and noble minds, the decay of exalted genius. Like the historian and antiquarian wandering with a sad heart over ground made classical and memorable in the story of great men, and of the annals of heroic deeds, - surveying with painful interest the crumbling ruins of ancient temples, - viewing with subdued emotion the almost extinguished remains of proud imperial cities, consecrated by the genius of men renowned in the world's history as scholars, artists, philosophers, and poets, so it is our duty to wander through the sad ruins of still greater temples than any that were in ancient days raised to the honour of an unseen DeIry. Yes, it is our distressing province to witness great and good intellects, proud understandings, levelled to the earth and crumbled like dust in the balance, under the dire influence of disease. Survey that old man crouched in the corner, with his face buried in his hands. He is indifferent to all that is passing around him-he heeds not the voice of man nor woman-he delights not in the carolling of birds or in the sweet music of the rippling brooks. The gentle wind of heaven, playing its sweetest melody as it rushes through the green wood, awakens no consciousness of nature's charms. Approach and speak to him. Address him in terms of endearment and affection; bring before him the glowing images of the past. He elevates his head, gazes listlessly and mechanically at you, "makes no sign," and, dropping his poor head, buries it in his bosom, and sinks into his former moody state of melancholy abstraction. This man's oratory charmed the senate-the magic of his eloquence held thousands in a state of breathless admiration; his influence was commanding, his sagacity and judgment eminently acute and profound. View him as he is fallen from his high and honourable estate. Listen to the sweet and gentle voice of yonder woman, upon whose head scarcely eighteen summer suns have shed their genial warmth and influence. How merrily she dances over the green sward! How touchingly she warbles, like poor Ophelia, sweet snatches of song! What a pitiful spectacle of a sweet mind lying in fragments before us! Look, she has decked herself with a spring garland. Now she holds herself perfectly erect, and walks with queenly majesty. Approach her side, accost her, she exclaims, "Yes, he will come; he promised to be here; where are the guests? where's the ring? where's my wedding dress-my orange flowers?" Suddenly her mind is overshadowed, and her face assumes an expression of deep choking and bitter anguish-she alternately sobs and laughs-is gay, sad, cheerful, and melancholy-

\section{"Thought and affliction, passion, hell itself, she turus to favour and to prettiness."}

Speak again to her, and another change takes place in the spirit of her dream. Like her sad prototype, the sweetest creation of Shakspeare's immortal genius, she plaintively sings :- 
"He is dead and gone, ladyHe is dead and gone; At his head a green grass turf, At his hecls a stone."

Her history is soon told. Deep and absorbing passion, elevated hopes, bright and fanciful dreams of the future-DEATH, with all its sad trappings and solemn mockery-seared affections, a broken heart, and a disordered brain. In its sad ruin, her mind retains much of jts native purity, innocence, and sweetness.

It is not my object to bring before you painful, fanciful, and imaginative sketches. The two iliustrations $I$ have cited are faithful and truthful outlines of cases that must have come under the notice of us all. How keenly cases like these tend to call into active operation all the kindly sympathies of our nature.

Having considered thus briefly the character of our vocation and the grave responsibilities of our position, I would, with great submission to the members of this Association, dwell shortly on the present state of that section of psychological science more immediately connected with the practical pursuits in which we are in common engaged - viz., that of the care and treatment of the insane.

At the onset I would premise that, as a body of men engaged in a holy and sacred office, we must not close our eyes to the fact that our position is not what we have a right to expect or are entitled to claim. Our studies, beyond a doubt, are ennobling and elevating; our duties, if conscientious!y discharged, excite into action the tenderest feelings of the heart, and the highest capaci ies of the intellect. To an intimate knowledge of the general characteristics of disease, and the sciences of pathology and therapeutics, which we possess in common with other sections of our profession, the psychological physician must unite a profound knowrledge, not only of the mind, but of mind as manifesting itself in charucter and human nature, in the most enlarged acceptation of these terms. He has to battle with the intellect in a condition of aberration; he has to combat with passions in a state of morbid exaltation; he has to administer to the feelings, affections, and appetites in a deranged or porverted condition; he has, in the exhibition of his moral remedial agents, emphatically to act upon mind as well as upon matter; and if he is unqualified by natural aptitude, by educntion, habits of thought, and careful study of the higher branches of philosophy, to perform such duties, he is obviously unfit for the post he is called upon to occupy. If such are the recognised characteristics of the psychological physician, why is he considered by the public, to a certain extent, as a man engaged in the pursuits of commerce and trade? How is it that a psychological expert, when in the witness-box, is so often subbed and browbeaten? Why should we, when engaged in the practical execution of our duties, be viewed and estimated as persons pursuing a degrading and dishonourable calling? Why should the finger of derision and scorn be pointed at us? Why should we be singled out from the crowd, and have flung in our faces the odions, offensive, and repulsive designation of "mad doctor," when called upon as experts to assist in the solemn administration of justice? I ask, why such a state of things should exist?- why men engaged in so honourable, sacred, and dignified a pursuit should occasionally find themselves in a position so false, painful, and humiliating? In justice to ourselves, as well as to those unhappy persons confided to our care, we are bound to consider this matter with becoming seriousness. The question cannot be blinked. There must be something "rotten in the state" to justify such a sad condition of things. We do not occupy our lesitimate position in public estimation, and it is our duty to ask why such shonld be the case? Having given this question much anxious consideration and thought, I have come to the following conclusions:-According to my apprehension, there are THREE modes of accountium $\frac{f}{1}$ or our present status. In the first place, I attribute mnch of the existing exil to the conduct of a few narrow-minded and ignorant men who have improperly had the care of the insane, anrl who have, by their very questionable proceedings, in a neasure legraded us all to their own imnoble level. Have we been true to ourselves? Is it necessary that we should look much away from home to find the arlverse causes that have been operating to our decradation and disparagement? Have we not made merchandise of the insane? Have we not been disposed to consiler their care and treatment more as a question of commerce than of science? Gentlemen, I am occasionally overpowered with feelings of deep humiliation and shame, when $I$ take up the advertisement sheet of the Times newspaper, and see to what measures men will resort to bring themselves, their houses, and their asylums prominently before the public, with a view to their personal aggrandisement. Not satisfied with advertising their estiblishments in the glowing, fauciful, poetical, and flowery language of an auctioneer, they go a step in advance, and offer liberal percentages and bonuses to all medical men patronising their institutions. Again, how often we see asylnms and their unhappy inmates brought into the market and offered for sale, like a llock of sheep, to the highest bidder, in a manner calculated to destroy all public contidence and trust in the honesty, integrity, and even common respectability of those connected with similar institutions. Consider for a moment the practical effect upon the public mind, and by reflex action upon the position of the psychological physician, of the following advortisement. I copy it, with addenda, from the last number of Punch:

"Any medical man who wants to get rid of an insane patient, or knows anybody that wants to get rid of an insane relation, will, perhaps, find the means of accomplishing his object, or that of the other party, by the help of the subjoined advertisement; for which he is recommended to search the recent numbers of all the daily papers, in one of which it is quoted from a medical journal:-

"INsiviTy.-Twenty per cent. annually on the receipts will be guaranteed to any inedical man recommending a quiet patient of either sex, to a first-class asylum, with the highest testimonials. Address _.."

"Twenty per cent. on the receipts for the board, lodging, and care of the unhappy lunatic, screwed out of the lunativ's board and lodging, would probably represent a considerable abridgment of the patient's natural life. On the other hand, to be sure, the advertising madhouse keeper would have an interest in prolonging the existence of his unfortunate charge; and, moreover, he might easily cheat the medical man out of the guaranteed twenty per cent., which surely would be a consideration, secured by a no more valid bond than a contract entered into for an immoral purpose."

This is not an isolated illustration. No number of The Times appears without containing announcements of a similur cha racter. Thank God! the great body of men engaged in the treatment of the insane would sooner permit themselves to be reduced to the lowest depths of poverty and distress than resort to such unprofessional means to advance their interests in life.

If we desire to elevate ourselves in the estimation of good men; if it is our object to secure for our specialty a legitimato position in public opinion, it is our duty to enter our firm pro test against proceedings like these; to hold no converse, com panionship, or communion with men who thus degrade them. selves to the condition of the common trader and shopkeeper, without any portion of the respectability, honesty, and worth which so commonly distinguishes men engaged in the legitimate pursuits of commerce.

To remedy this great and growing evil we must in the first place put our own houses in order-

$$
\begin{aligned}
& \text { Our remedies oft in ourselves do lie } \\
& \text { Which we ascrily to hesven; the fated sky } \\
& \text { Gives us free scope; only doth backward pull } \\
& \text { Our slow designs, when ve ourselves are dull." }
\end{aligned}
$$

It is now my duty to consider the second cause operating to our disadvantage-viz., the effect of legislative enactments upon the character of the psychologists, and the cond tion of the insane.

The legislature has never fully recognised or admitted the important principle that insanity is a pathological condition; in other words, that it is a type of diseased manifestation. This great first principle should be prominently recorded in the preamble of every parliamentary enactment relating. to the treatment of the insane, and all legislation should be based upon the full and liberal recognition of the fact that insanity, lencey, unsound ncsis of mind, idiotcy, imbecility - to nse the common legal phrasedlogy-are curable states of bodily and braiu disease, disordering the manifestations of the mind; and that in the organization of all institutions for the care and treatment of the insane, as well as in the distribution of licences to persons willing to undertake the management of this class of affections, the first question to bo considered is, whether the party is fitted by education, knowledge, and experience for the performance of his responsible duties? I would permit no one to have the legal charge and treatment of either an acute or chronic case of mental aberration who was not a qualified medical man. As long as licences are granted to non-professional persons, as well as to women, the public will be indisposed to believe that insanity is the result of a physical morbid condition of the brain, or of some organ in close sympathy with it; or that the disease is one amenable to remedial medical treatment. The non-recognition of this important elementary 
principle in the past legislation on this subject of lunacy has undoubtedly had the effect, not only of encouraging in the public mind erroneous views of the nature and treatment of insanity, but of placing the psychological physician in a false commercial position. And why should such be the case? The qualified and educated medical practitioner who has an asylum for the treatment of his own patients finds himself placed in the same category with non-professional men and women, into whose hands are entrusted the legal custody and treatment of the insane. It is obvious that this course of procednre must inevitably tend to depreciate the character of all connected with asylums, and lower the psychologist in his own as well as in public estimation.

What has been the natural consequence of permitting nonfessional persons to have the care of the insane? Persons palpably unfitted for the right and humane performance of so solemn a trust have been discovered seriously and wilfully neglecting the interest of those entrusted to their legal guardianship. The evil has been fully recognised by the state, and from time to time various legislative enactments for the protection of the insane have become part of the statute law of the land, so constructed as to meet the exigencies of the case, and, if possible, avert a recurrence of these evils. Stringent legal clauses have found their way into these various lunacy enactments, until we may be said to act under the authority of a bill of pains and penalties. I do not complain of the operation of these measures; I refer to the fact simply with a view of establishing my position, that owing to the charazter of a few of those who have in former years had the care and treat ment of the insane, such stringent laws have been deemed essentially necessary for their safety and protection.

It is not my intention to consider in detail the various existing Lunacy Bills for the purpose of satisfying you that the provisions of the present law operate prejudicially to the interests of psychology, and are seriously detrimental to those connected with the care of the insane. I will cite but one illustration of the fact.

Agreeably to the provisions of a former enactment, no medical man was held to be legally qualified for the post of a commis sioner in lunacy who had any interest, direct or indirect, in the confinement of the insane for one year previously. This clause was altered in the last Act of Parliament, the one now in operation; and in conformity with the amended Bill, no medical man is eligible for the office of commissioner who has had for two years an interest, direct or indirect, in the confinement of the insane; in other words, who has not been disconnected with a private asylum for a period of two years, the legislature not considering one year a sufficient time to restore the mind of the psychological physician to a state of judicial purity.

So great is the contamination and degradation incidental to a conuexion with an asylum, that the Legislature, in its profound wisdom and commendable sagacity, considers two years purgation necessary before the medical man can be viewed as qualified to sit at the board of commissioners, and assist in the administration of the law! Upon what principle was such a clause introduced into the Lunacy Bill ?

I fully admit that no person appointed to so important an office should have the most remote interest, direct or indirect, in the care and treatment of the insane, and that before accepting an appointment of the kind, and prior to his taking the oaths of office, he should be in a position to say that he has entirely ceased to have the slightest or faintest sbadow of interest in the confinement of any one insane individual; but it puzzles my simple understanding to comprehend why the law should require two years of cleansing and purification on the part of rentlemen engaged in the solemn and faithful discharge of professional duties before they can be considered fitted for sueb an appointment.

I should be insulting the understanding of those $T$ have the honour to address, if $I$ were to occupy any time in attempting to demonstrate the practical effect of such a provision of the law upon the character and position of all engaged in the study of psychology, and in the care and treatment of the insane. Whatever tends to lower in public estimation the psychological physician, whether connected or unconnected with a private asylum, must materially, seriously, and, without doubt, injuriously affect also those connected with our public institutions. Apart from the mischief such a state of the law must inflict upon the great body of psychological pbysicians, consicler for one monent the serious injustice it does to a number of physicians engaged in private practice, and who, in a measure, are compelled to be associated with private asylums. These men are disfranchised, virtually excluded from the office of commis sioner. Irrespectively of a man's reputation, character, and experience, be is legally disqualified if he retains any interest in the confinement of a single insane person.

$I$ have no hesitation in asserting that this is an anjust, a mischievous, and an iniquitous enactment. I can conceive $\mathbf{a}$ man of European reputation, of great practical knowledge, of unbounded experience, of profound sagacity, of high and unimpeachable honour and character, looking forward at the close of a brilliant and useful career to an appointment of this nature, as one of the prizes which should be awarded to professional men whose great public services and talents were entled to some slight recognition. This man would be ineligible for the office the duties of which he was admirably fitted to discharge unless for two years he had ceased to have any interest in the confinement of the insane! Profound legislators! Wise statesmen! Eminent and sagacious senators! to have conceived so enlightened and benevolent an enactment!

In considering the third cause which has operated to the disadvantage of the psychologist, I must be brief. The ignorance exhibited by the public of the real characteristics of insanity and of the treatment necessary for its cure is certainly great. Poets, Dramatists, and Novelists have materially aided in promulgating fictitious, imaginative, and consequently erroneons notions of insanity.

From this imputation I, of course, except our own immortal bard, that great magician whose towering genius, profound wisdom, extraordinary and intimate insight into the secret workings of the human mind and heart, and whose universal knowledge, shed a brilliant flood of light upon every snbject to which he directed the power of his gigantic intellect. His delineations of insanity must ever be viewed as master creations of beauty, grace, loveliness, and truth. He was eminently the great and gifted psycloologist of his epoch, and no man (and we have had great giants since his day) has yet been able distantly to approach him in his knowledge of the intellect either in its normal condition or in a state of aberration.

In conclusion, I would again repeat that we must look faithfully at our own hearts, and honestly analyze our own motives, and conscientiously scrutinize our own conduct, if we desire to discover the true cause of the present unsatisfactory status of the psychological physician, and are anxious to elevate our body in the social scale.

Having said so much about ourselves, let me finally add a few words respecting those who are placed under our special care and protection. We cannot too frequently allow our minds to dwell upon the peculiar state of those reduced by insanity to a condition of utter and childish helplessness. In other classes of disease, in which the functions of the brain remain intact, the invalid, even while suffering the most acute and agonising pain, bodily distress, and physical prostration, is in a state to appreciate his actual relations with those around him-he feels sensibly the exhibition of tender sympathy-he properly estimates the care and attention bestowed upon his case, and recognises the skill of his faithful medical adviser. Alas! how different are the feelings and thonghts of many of the insane! In this class of affections the kindness, sympathy, skill, unremitting assiduity and attention of the physician are often not outwardly or manifestly appreciated. He has, in many cases, to pursue his holy work without the exhibition of the slightest apparent consciousness on the part of the patient of his efforts to mitigate his condition of mental disease and bodily suffering. Nevertheless, it is our sacred duty, even where, as is occasionally the case, onr actions are greatly misconstrued, and our remarks perverted, by those to whose relief we are administering, to unflaggingly persevere in our efforts to carry out our curative process of treatment. Our poor unhappy invalid may believe that we are acting the part of his bitterest foe. This ought not to excite in our mind any feeling but that of the most profound love and sympathy. If his language be offensive and repulsive-if he be guilty of any acts of violence towards those in attendance upon him-let us never for a moment lose sight of the fact that his unhappy affliction has to a degree destroyed his free will, and that he, for a time, has ceased to be a responsible being. It would be cruel, whilst such a condition of nind exists, to treat such a patient otherwise than as a person deprived by disease of complete selfgovernment and moral control. I feel how unnecessary it is for me to urge upon those connected with this Association-to all engaged in the treatment of the insane, the importance of never losing sight of the fact, that even in the worst form of mental disease there are some salient and bright spots upon which we may act, and against which we may direct our most potent curative agents. How true it is that-

"There is some soul of goodness in things cril, Would men observingly distil it out" 
The more formidable, and apparently hopelessly incurable, types of mental derangement admit, if not of cure, at least of considerable alleviation and mitigation. We should never say of a case of insanity that it is incurable, or that it baffles our skill. We undoubtedly possess the power of materially modifying, if we cannot entirely re-establish, the mental equilibrium, the most unfavourable and distressing forms of insanity, rendering the violent, the turbulent, tractable and amenable to discipline-the dangerous, harmless-the noisy, quiet-the dirty, cleanly in their habits-the melancholy, cheerful-by a careful study of the bodily or mental condition of each individual case, and by an unremitting attention to dietetic and hygienic regimen, as well as by a persevering, unflagging, and assiduous administration of physical and moral remedies for their relief.

The spirit of love, tender sympathy, Christian benevolence, unwearying kindness, and warm affection, should influence our exery thought, look, and action, when engaged in the treatment of the sad and distressing cases entrusted to our care. We should never forget that, to use the felicitous and truthful language of the bard of Avon, it is the special province of the psychological physician to

"Fetter strong madness in a silken thread,

Charm ache with air, and agony with words."

Oh, what a holy, honourable, and sacred occupation is that in which we all have the privilege to be engaged! The gods might well envy us the ennobling and exalted pleasures incidental to our mission of love and charity.

\section{(T) ortesponotire.}

"Audi alteram partem."

\section{HOSPITAL PHYSICIANS AND SURGEONS.}

\section{To the Editor of The LANCET.}

Sir,-I appeal to you, the father of Medical Reforms, for your powerful advocacy in the cause of the rising generation of hospital physicians and surgeons. We are the victims of a polity which is daily becoming more burdensome and oppres. sive, and must, in candonr admit, that the rifficulties of our position leave us little hope of redress. We are much indebted to TH: LAxCET for the publicity and discussion which have been freely afforded us, and much has been done in consequence; but it seems of late the subject has either exhausted the zeal of its friends, or, in sheer hopelessness, they have abandoned it. Am I presuming too much in this attempt to fan the expiring embers? If not, may $I$ ask to be allowed to raise our ensign, and rally our ranks in THE LANCET? I desire, then, to recall public attention to the case of the hospital physicians and surgeons; and though my remarks will more immediately apply to that of the London hospitals, they will not be inapposite to that of our brethren in the provinces.

In the first place, let us take a glance at the qualifications, \&c., of those occupying hospital appointments. The physician or assistant-physician to a metropolitan hospital must be a member of a college of physicians of Great Britain or Ireland, (generally London;) the surgeon or ass stant-surgeon, a fellow of a college of surgeons, or, in the case of the assistant, a member. As a consequence, the medical officers are at least twenty-six years of age, and have generally graduated in arts and medicine in a British university, and have subsequently earned their promotion by filling the chair of physics, botany, or morbid anatomy, or by acting as registrar or curator of the museum, or in some other capacity equally unprofitable in the hospital or college attached. The surgeons, though seldom graduates, are equally men of standing, accomplished anatomists, or have won their title to nomination by long years of weary and unproductive labour. Now, suppose a vacancy, up rise half a dozen candidates, a tedious personal canvass (equal to that of a county member at least) ends in winning or losing at a cost of several hundred pounds. The unsuccessful candidates await the next turn-" still out of reach, but never out of view :" mine have grown gray on hope. The elect then enters on his duties, and he fondly persuades himself that after all his anxiety, toil, suspense, and outlay, he will soon begin to reap some tangible fruits of his labours. The terms of his appointment require that he shall practise as a physician, or surgeon, " pure," as the case may be. The etiquette of the profession compels him to place himself on a par with Sir James or Sir Benjamin as to fees. He of course resides in such a house as a man of his dignity may be expected to occupy, endeavours to sustain the appearance of a gentleman, continues to consume " the midnight oil," and by all means to render himself worthy of his office. As an assistant, he takes charge of 100 to 200 out-patients, whom he passes in review twice a week; and, in addition, performs such duties as may devolve on him by the absence of his senior colleague. Should that dignitary be the victim of old age, indolence, or other infirmity, which causes him to bear his burden lightly, the junior, at a moment's notice, may be called on (regardless of his own interests) to take vicarious duty. His concluct as an officer is strictly scrutinized by a lay committee, sometimes more exacting than courteous; he is at all times, and under all circumstances, bound to strict punctuality in the discharge of his duties, failing which he receives a smart philippic, and is reninded that public duties claim his first attention. Again: in undertaking this important charge, he finds he has very much restricted the sphere of his movements; for the governors have decreed that the only terms on which he may absent himself are by providing the services of a colleague; consequently, when weary of the hum and toil of this " modern Babylon," he seeks repose, and to recruit his exhansted frame, (for he is but a mortal, and even steam-engines wear out,) he incurs a debt which can only be remitted in kind, on his return, by doing double duty.

The facts that all this responsibility and restriction, which impose on the officer such devotion, and exact so large a part of the available working hours of his life, are absolutely unpaid, and that when exhausted, weary, and depressed, as a man must be who has done his best for a hundred poor sufferers, with whom he has been incarcerated for some hours, breathing an atmosphere at all times polluted in such an assemblage, and often pestilential, he returns to his home empty as he left it, to seek some profitable employment, are known to comparatively few. Doubtless a man has thus many opportunities of gaining the confidence and gratitude of his patients, and of thus building a fame which may ultimately raise him into private and profitable practice; but ill health or other unforeseen circumstances may deprive him of those denrly-won fruits of his labours. Few, J. am sure, of the munificent benefactors of these enduring monuments of the charity which animates our countrymen are aware that these great blessings to the desolate sick thus depend on the unrewarded labours of the medical staff, and fewer still, I hope and believe, would decline to render us a less precarious consideration for our services. But years roll on; the seniors win their way to fame, gather their laurels, or are gathered to their fathers, and the juniors take their places; "by turns we catch the vital breath and die;" their gray hairs replace their once luxuriant locks, (unless time has been too relentless;) they then begin to reap some of the fruits of office, such as the fees of pupils at the hospital, and obtain such practice as years of accumulative labours and standing bring them. This, and this only, has been the junior's hope. The public considers that the title of assistant does not convey much; and as some seniors retain their honours with donbtful adrantage to the hospital and themselves, long deferring the promotion of their colleagues, (which with few honourable exceptions cannot be gained by a limited service, though clearly so reasonable and advantageous to the institution and the staff,) thus even this adventitious advantage may be indefinitely postponed.

When these appointments were originally instituted, the profession, as a mass, was infinitely worse informed, and therefore in a less degree possessed public confidence; but as the system of hospital relief extended, the great body of practitioners has become more enlightened, and thus the want of consulting physicians and surgeons has diminished. Competition is now so great, that the junior has but little chance of private practice; consequently, unless he be a man of property, he cannot afford to wait his turn. The public may be, and often is, deprived of "the right man in the right place ;" or if a young man of talent, but not of money, attempt the hospital career, his distraction in the struggle of life robs the public of that developed talent of which only the young and plastic mind is susceptible.

Under the enlightened policy of the continental regime, the young medical officer possesses, by virtue of his appointment, a certain adequate consideration, which enables him to devote his early life to the cultivation of his profession, and produces the fruit of an early harvest. As all real advancement of medical science benefits the public rather than the profession, (for few men discriminate between the unsuccessful though deserving, and the successful and plausible, therefore it is for the public good that these great schools of Nature should be made 